\title{
NMR resonance assignments of the PR-10 allergens Act c 8 and Act $d 8$ from golden and green kiwifruit
}

\author{
Ricarda Zeindl ${ }^{1}$ (D) Martin Tollinger ${ }^{1}[$
}

Received: 19 March 2021 / Accepted: 1 June 2021 / Published online: 9 June 2021

(c) The Author(s) 2021

\begin{abstract}
Kiwifruits have become one of the most common food sources triggering allergic reactions. In patients suffering from birch pollen related food allergy, reactions result from initial sensitization to the birch (Betula verrucosa) pollen allergen Bet $\mathrm{v}$ 1 , followed by immunological cross-reactivity to structurally homologous proteins in kiwifruit. Clinical symptoms range from scratching and itching of the oral cavity to more severe immunological reactions such as rhino conjunctivitis. In this work we assigned backbone and side chain ${ }^{1} \mathrm{H},{ }^{13} \mathrm{C}$ and ${ }^{15} \mathrm{~N}$ chemical shifts of the $17 \mathrm{kDa}$ PR-10 allergens Act c 8.0101 and Act d 8.0101 from golden (Actinidia chinesis) and green (Actinidia deliciosa) kiwifruit by solution NMR spectroscopy. The chemical shift data confirm the characteristic Bet v 1 fold for both proteins, consisting of a seven-stranded antiparallel $\beta$-sheet interrupted by two short $\alpha$-helices, along with a long C-terminal $\alpha$-helix. Our data provide the basis for determining the threedimensional solution structures of these proteins and characterizing their immunological cross-reactivity on a structural basis.
\end{abstract}

Keywords NMR resonance assignment $\cdot$ TALOS + prediction $\cdot$ PR-10 protein $\cdot$ Cross-reactivity $\cdot$ Allergen

\section{Biological context}

The most common allergy in Western and Central Europe is pollinosis, elicited by sensitization to birch pollen. About 70-90\% of birch pollen allergic patients show IgE serum reactivity against the major birch pollen allergen Bet $\mathrm{v} 1$ (Ipsen and Lowenstein 1983; Moverare 2002). Patients suffering from birch pollinosis frequently experience allergic reactions after consumption of certain fruits and nuts, due to immunological cross-reactivity of Bet $\mathrm{v} 1$ specific antibodies (IgE) to proteins that are present in these food sources. Symptoms typically occur immediately after consumption and are mostly confined to the oral allergy syndrome, which includes itching and scratching of the throat and tongue (Mari et al. 2005). Around 50-60\% of all individuals, who are sensitized towards birch pollen, exhibit allergic reactions after consumption of kiwifruit (Geroldinger-Simic, 2011; Le, 2013). Kiwifruit are of high nutritive and health value, with an exceptionally high vitamin $\mathrm{C}$ content (Hunter

Martin Tollinger

martin.tollinger@uibk.ac.at

1 Institute of Organic Chemistry, Center for Molecular Biosciences Innsbruck (CMBI), University of Innsbruck, Innrain 80/82, 6020 Innsbruck, Austria et al. 2011). Kiwifruit allergic patients avoid eating the fruit, thereby abstaining themselves from a valuable food source.

Immunological cross-reactivity to birch pollen is associated with the class 10 pathogenesis related (PR) proteins, Act c 8 and Act d 8, from golden (Actinidia chinensis) and green (Actinidia deliciosa) kiwifruit (Oberhuber, 2008). The expression of these proteins, which are believed to play a major role in plant defense, can be induced by pathogenic or environmental stress. PR-10 proteins consist of about 160 amino acid residues, with a molecular weight of 17-18 kDa. The canonical fold of PR-10 proteins consist of a sevenstranded antiparallel $\beta$-sheet $(\beta 1-\beta 7)$, which is interrupted by two short $\alpha$-helices ( $\alpha 1$ and $\alpha 2)$ between strands $\beta 1$ and $\beta 2$ and covered by a long C-terminal $\alpha$-helix (Fernandes et al. 2013). Similar to other PR-10 proteins, Act c 8 and Act $\mathrm{d} 8$ are easily degraded by proteolysis and are heat labile (Breiteneder and Mills 2005). In kiwifruit, the allergens Act c 8 and Act $\mathrm{d} 8$ are located in the peripheral pulp. ELISA and immunoblot experiments showed that recombinantly produced Act $\mathrm{c} 8$ and Act $\mathrm{d} 8$ are recognized and bound by $\operatorname{IgE}$ in sera of birch pollen allergic patients in vitro, suggesting clinically relevant levels of immunological cross-reactivity with Bet v 1 (Oberhuber et al. 2008).

While the presence of multiple isoforms of Act c 8 and Act $\mathrm{d}$ 8, which may possess differential IgE binding 
potentials, is likely in kiwifruit, only a single isoform of each allergen has been identified so far. Among each other Act d 8.0101 (CAM31909) and Act c 8.0101 (CAM31908.1) share a sequence identity of $70 \%$, while the sequence identity with the birch pollen allergen Bet v 1 is only $53 \%$ and $54 \%$, respectively (Gajhede, 1996). The sequence identity of these two kiwi allergens with the most prominent crossreactive food allergen, Mal d 1 from apple, is 57\% and 58\% (Ahammer et al. 2017, 2016). A peculiar feature of the two PR-10 allergens from kiwifruit is their unusually high number of cysteine residues.

In this work we present the solution NMR backbone and side-chain assignments of the two recombinantly expressed allergens Act $\mathrm{d} 8$ and Act c 8 .

\section{Methods and experiments}

\section{Sample preparation}

The codon-optimized inserts of Act c 8.0101 (GenBank nucleotide code AM489567.1 and protein code CAM31908.1) and Act d 8.0101 (GenBank nucleotide code AM489568 and protein code CAM31909) were each cloned in the expression vector pET28b (+) using restriction enzymes NcoI and XhoI. Transformation was conducted in the E. coli strain BL21(DE3) Star (Invitrogen). A starter culture $(20 \mathrm{~mL})$ of Luria Bertani (LB) medium with $25 \mu \mathrm{g} /$ $\mathrm{mL}$ kanamycin was inoculated with one bacterial colony and incubated for $8 \mathrm{~h}$ at $37{ }^{\circ} \mathrm{C}$ and $200 \mathrm{rpm} .20 \mu \mathrm{L}$ of the starter culture were transferred into $100 \mathrm{~mL}$ of M9 minimal medium and incubated overnight at $37{ }^{\circ} \mathrm{C}$ and $200 \mathrm{rpm}$. To reach a starting cell density of 0.1 in the final expression culture, the necessary volume of the overnight culture was calculated by $\mathrm{V}_{\mathrm{o} / \mathrm{n}}=\left(0.1 \times \mathrm{V}_{\text {expression }}\right) / \mathrm{A}_{600, \mathrm{o} / \mathrm{n}}$. The appropriate volume was centrifuged at $2000 \times g$ and the pellet was resuspended in $1 \mathrm{~L}$ of $\mathrm{M} 9$ minimal medium enriched with either ${ }^{15} \mathrm{NH}_{4} \mathrm{Cl}(1 \mathrm{~g} / \mathrm{L})$ or ${ }^{13} \mathrm{C}_{6}$-D-glucose $(3 \mathrm{~g} / \mathrm{L})$ and ${ }^{15} \mathrm{NH}_{4} \mathrm{Cl}$ (both Cambridge Isotope Laboratories) and supplemented with $25 \mu \mathrm{g} / \mathrm{mL}$ kanamycin. The culture was incubated at $37^{\circ} \mathrm{C}$ and $200 \mathrm{rpm}$ until the cell density reached $0.5-0.6$ (at $600 \mathrm{~nm}$ ), at this point, protein expression was induced by addition of isopropyl- $\beta$-D- 1 -thiogalactopyranoside (IPTG, $1 \mathrm{mM}$ ) and performed for $3 \mathrm{~h}$ at $37^{\circ} \mathrm{C}$. Cells were harvested at $4{ }^{\circ} \mathrm{C}$ and $4600 \times g$ for $40 \mathrm{~min}$, resuspended in a buffer containing $0.5 \mathrm{M}$ urea, $25 \mathrm{mM}$ imidazole and $0.1 \%$ Triton $\mathrm{X}-100$ and stored until usage at $-80{ }^{\circ} \mathrm{C}$. For lysis, cells were thawed, treated for $40 \mathrm{~min}$ on ice with lysozyme $(10 \mu \mathrm{g} / \mathrm{mL})$ and DNAse $(1 \mu \mathrm{g} / \mathrm{mL})$, passed through a French Press and centrifuged at $16,000 \times g$ and $4{ }^{\circ} \mathrm{C}$ for $45 \mathrm{~min}$. The filtered $(0.45 \mu \mathrm{m})$ lysate was loaded onto an anion exchange column (Resource Q $6 \mathrm{~mL}$, GE Healthcare) and Act d 8.0101 or Act c 8.0101 protein was eluted with a sodium chloride gradient over $30 \mathrm{~mL}$ from 0 to $50 \%$ in $25 \mathrm{mM}$ TrisHCl buffer (pH 7.5) at a flow rate of $2 \mathrm{~mL} / \mathrm{min}$. Fractions containing the desired protein were concentrated to about $1.5 \mathrm{~mL}$ by centrifugation (Amicon Ultra $3 \mathrm{kDa}$ MWCO, Merck Millipore) and loaded onto a size exclusion column (HiLoad 16/600 Superdex $75 \mathrm{pg}$, GE Healtcare) for the final purification step and eluted isocratically at $1 \mathrm{~mL} / \mathrm{min}$ with a $20 \mathrm{mM}$ sodium phosphate buffer ( $\mathrm{pH}$ 6.9). Both allergens eluted with a retention time that is in accordance with monomeric PR-10 proteins (Ahammer et al. 2016). SDS-PAGE gel electrophoresis was used to monitor all purification steps. NMR samples were prepared containing $0.5 \mathrm{mM}{ }^{15} \mathrm{~N}$ labeled and ${ }^{15} \mathrm{~N} /{ }^{13} \mathrm{C}$ labeled protein, supplemented with $10 \% \mathrm{D}_{2} \mathrm{O}(\mathrm{v} / \mathrm{v})$. No reducing agents were added to NMR samples or during purification.

\section{NMR spectroscopy}

All NMR spectra were recorded at $25^{\circ} \mathrm{C}$ on $500 \mathrm{MHz}$ Agilent DirectDrive 2 and $700 \mathrm{MHz}$ Bruker Neo Avance spectrometers equipped with room temperature triple-resonance probes. A two-dimensional ${ }^{1} \mathrm{H}-{ }^{15} \mathrm{~N}-\mathrm{HSQC}$ and three-dimensional $\mathrm{HNCACB}, \mathrm{CBCA}(\mathrm{CO}) \mathrm{NH}, \mathrm{HN}(\mathrm{CA}) \mathrm{CO}$ and $\mathrm{HNCO}$ experiments were used to obtain the backbone resonance assignments. Additionally, a two-dimensional ${ }^{1} \mathrm{H}-{ }^{13} \mathrm{C}-\mathrm{HSQC}$ and three-dimensional (H)CC(CO)NH-TOCSY, H(CCO) NH-TOCSY, ${ }^{1} \mathrm{H}_{-}{ }^{15} \mathrm{~N}-\mathrm{TOCSY}$-HSQC,${ }^{1} \mathrm{H}_{-}{ }^{15} \mathrm{~N}$-NOESYHSQC and ${ }^{1} \mathrm{H}^{-13} \mathrm{C}$-NOESY-HSQC experiments were used for side-chain assignments. Aromatic side-chains of phenylalanines and tyrosines were assigned with aromatic ${ }^{1} \mathrm{H}-{ }^{13} \mathrm{C}$ HSQC experiments. Data was processed with NMRPipe (Delaglio et al. 1995) and the CcpNMR software package was used for resonance assignment (Vranken, 2005).

\section{Assignments and data deposition}

We were able to assign the backbone amide resonances of 145 (out of 151) non-proline residues for Act c 8.0101 (Fig. 1a) and 146 (out of 150) non-proline residues for Act d 8.0101 (Fig. 1b). The ${ }^{1} \mathrm{H}_{-}{ }^{15} \mathrm{~N}-\mathrm{HSQC}$ spectra of the two allergens are indicative of well folded proteins in solution (Table 1).

The accession numbers at the Biological Magnetic Resonance Data Bank (http://www.bmrb.wisc.edu) are 50811 for Act d 8.0101 and 50812 for Act c 8.0101. We used the TALOS + software (Shen et al. 2009) to predict the secondary structure elements of the two allergens based on their $\mathrm{H}^{\mathrm{N}}, \mathrm{N}, \mathrm{C}^{\prime}, \mathrm{C}^{\alpha}$ and $\mathrm{C}^{\beta}$ backbone chemical shifts. Although both allergens only share a sequence identity of $70 \%$, illustrated by the sequence alignment (Fig. 2a), the NMR chemical shifts for both Act c 8 (Fig. 2b) and Act d 8 (Fig. 2c) agree with the canonical PR-10 secondary structure, containing seven $\beta$-strands ( $\beta 1-\beta 7)$, interrupted by two short $\alpha$-helices ( $\alpha 1$ and $\alpha 2)$, and a long $\alpha$-helix at the $\mathrm{C}$-terminus. 
Fig. $1700 \mathrm{MHz}{ }^{1} \mathrm{H}_{-}{ }^{15} \mathrm{~N}-$ HSQC of a Act c 8.0101, and a $500 \mathrm{MHz}{ }^{1} \mathrm{H}_{-}{ }^{15} \mathrm{~N}-\mathrm{HSQC}$ b Act d 8.0101 (each $0.5 \mathrm{mM}$ ) in $20 \mathrm{mM}$ sodium phosphate (pH 6.9), supplemented with $10 \% \mathrm{D}_{2} \mathrm{O}$ at $25^{\circ} \mathrm{C}$. Assigned residues are indicated by single letter codes and horizontal lines indicate asparagine and glutamine $\mathrm{NH}_{2}$ side-chain resonances. Asterisks indicate the positions of residues below the intensity cut-off. Resonance assignments are available online at the BMRB repository (accession number for Act d 8.0101 is 50811 and 50812 for Act c 8.0101)

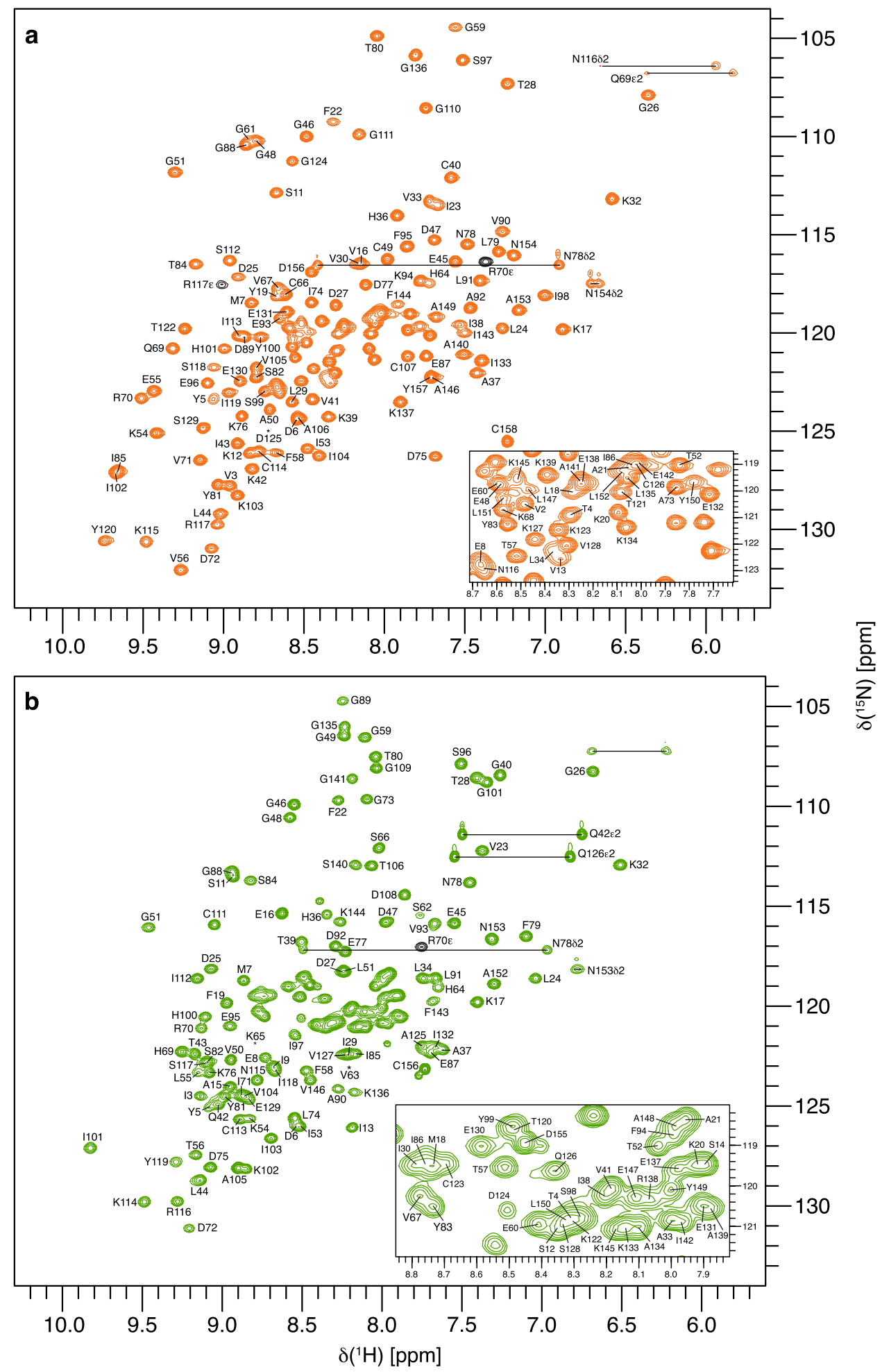


Table 1 Completeness of backbone and side-chain resonance assignments for the two PR-10 allergens from kiwifruit

\begin{tabular}{llc}
\hline & Act c 8.0101(\%) & Act d $8.0101(\%)$ \\
\hline $\mathrm{C}^{\prime}$ & 93.0 & 99.4 \\
$\mathrm{C}^{\alpha}$ & 97.5 & 99.4 \\
$\mathrm{C}^{\beta}$ & 97.3 & 100.0 \\
$\mathrm{C}^{\gamma}$ & 73.0 & 72.5 \\
$\mathrm{C}^{\delta}$ & 69.5 & 79.1 \\
$\mathrm{C}^{\varepsilon}$ & 72.2 & 87.5 \\
$\mathrm{H}^{\mathrm{N}}$ & 96.7 & 98.0 \\
$\mathrm{H}^{\alpha}$ & 92.4 & 94.5 \\
$\mathrm{H}^{\beta}$ & 94.3 & 95.7 \\
$\mathrm{H}^{\gamma}$ & 78.7 & 81.7 \\
$\mathrm{H}^{\delta}$ & 72.2 & 90.1 \\
$\mathrm{H}^{\varepsilon}$ & 79.7 & 86.8 \\
$\mathrm{~N}$ & 96.0 & 97.3 \\
$\mathrm{~N}^{\delta}$ & 42.9 & 28.6 \\
$\mathrm{~N}^{\varepsilon}$ & 42.9 & 33.3 \\
\hline
\end{tabular}

Assignment for backbone amides $\mathrm{H}^{\mathrm{N}} / \mathrm{N}$ corresponds to non-proline residues
The NMR resonance assignments of Act c 8 and Act d 8 obtained in this work will enable us to analyze structural and dynamic properties of these proteins in a comparative manner, and to investigate their immunological cross-reactivity in detail.
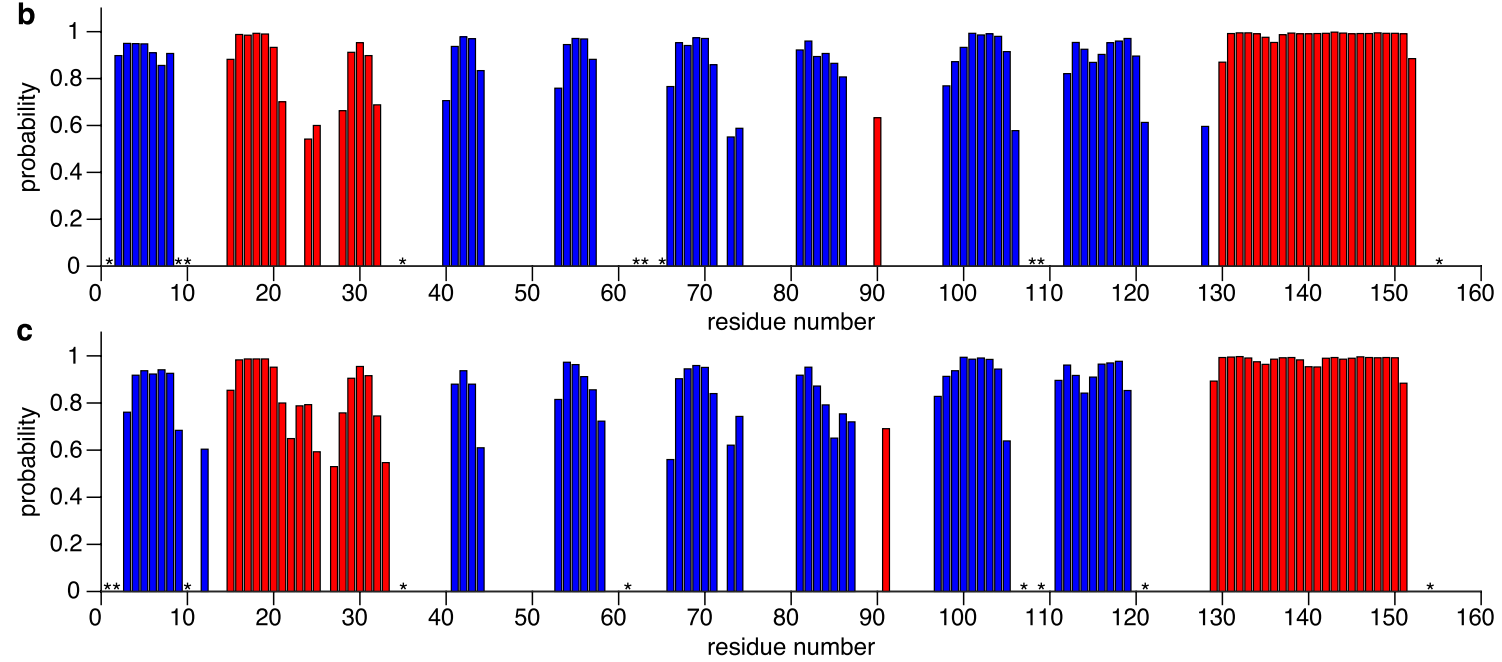

Fig. 2 a Sequence alignment of Act c 8.0101 and Act d 8.0101. Identical residues in the two proteins are marked by asterisks, while dots indicate different residues with weakly similar properties and colons indicate different residues with strongly similar properties (generated by Clustal Omega (Madeira 2019)). Secondary structure of b Act c 8 and $\mathbf{c}$ Act d 8 as predicted by TALOS + , based on $\mathrm{H}^{\mathrm{N}}, \mathrm{N}, \mathrm{C}^{\prime}, \mathrm{C}^{\alpha}$, and $\mathrm{C}^{\beta}$ chemical shifts. Secondary structure probabilities (red: $\alpha$-helices; blue: $\beta$-strands) are plotted versus residue numbers. Asterisks indicate residues for which backbone amide $\mathrm{H}^{\mathrm{N}} / \mathrm{N}$ resonance assignments are not available 
Acknowledgements Open Access funding was provided by the Austrian Science Fund (FWF). This work was supported by the Austrian Science Fund FWF (P26849) and the Austrian Research Promotion Agency FFG (Project 858017, West-Austrian BioNMR). We thank Dr. Thomas Müller, and Dr. Christina Meisenbichler for mass spectrometry experiments.

Funding Open access funding provided by University of Innsbruck and Medical University of Innsbruck.

\section{Declarations}

Conflict of interest The authors declare that they have no conflict of interest.

Ethical approval The authors declare that the experiments described in this publication were done in compliance with the ethical standards of the countries in which they were performed.

Open Access This article is licensed under a Creative Commons Attribution 4.0 International License, which permits use, sharing, adaptation, distribution and reproduction in any medium or format, as long as you give appropriate credit to the original author(s) and the source, provide a link to the Creative Commons licence, and indicate if changes were made. The images or other third party material in this article are included in the article's Creative Commons licence, unless indicated otherwise in a credit line to the material. If material is not included in the article's Creative Commons licence and your intended use is not permitted by statutory regulation or exceeds the permitted use, you will need to obtain permission directly from the copyright holder. To view a copy of this licence, visit http://creativecommons.org/licenses/by/4.0/.

\section{References}

Ahammer L, Grutsch S, Kamenik AS, Liedl KR, Tollinger M (2017) Structure of the major apple allergen Mal d 1. J Agric Food Chem 65:1606-1612. https://doi.org/10.1021/acs.jafc.6b05752

Ahammer L, Grutsch S, Tollinger M (2016) NMR resonance assignments of the major apple allergen Mal d 1. Biomol NMR Assign 10:287-290. https://doi.org/10.1007/s12104-016-9685-8

Breiteneder H, Mills EN (2005) Molecular properties of food allergens. J Allergy Clin Immunol 115:14-23. https://doi.org/10.1016/j.jaci. 2004.10.022

Delaglio F, Grzesiek S, Vuister GW, Zhu G, Pfeifer J, Bax A (1995) NMRPipe: a multidimensional spectral processing system based on UNIX pipes. J Biomol NMR 6:277-293. https://doi.org/10. 1007/BF00197809

Fernandes H, Michalska K, Sikorski M, Jaskolski M (2013) Structural and functional aspects of PR-10 proteins. FEBS J 280:1169-1199. https://doi.org/10.1111/febs.12114

Gajhede M et al (1996) X-ray and NMR structure of Bet v 1, the origin of birch pollen allergy. Nat Struct Biol 3:1040-1045

Geroldinger-Simic M et al (2011) Birch pollen-related food allergy: clinical aspects and the role of allergen-specific IgE and IgG4 antibodies. J Allergy Clin Immunol 127(616-622):e611. https:// doi.org/10.1016/j.jaci.2010.10.027

Hunter DC, Greenwood J, Zhang J, Skinner MA (2011) Antioxidant and "natural protective" properties of kiwifruit. Curr Top Med Chem 11:1811-1820. https://doi.org/10.2174/156802611796235 134

Ipsen H, Lowenstein H (1983) Isolation and immunochemical characterization of the major allergen of birch pollen (Betula verrucosa). J Allergy Clin Immunol 72:150-159

Le TM et al (2013) Kiwifruit allergy across Europe: clinical manifestation and $\mathrm{IgE}$ recognition patterns to kiwifruit allergens. J Allergy Clin Immunol 131:164-171. https://doi.org/10.1016/j.jaci.2012. 09.009

Madeira F et al (2019) (2019) The EMBL-EBI search and sequence analysis tools APIs in. Nucleic Acids Res 47:W636-W641. https://doi.org/10.1093/nar/gkz268

Mari A, Ballmer-Weber BK, Vieths S (2005) The oral allergy syndrome: improved diagnostic and treatment methods. Curr Opin Allergy Clin Immunol 5:267-273

Moverare R et al (2002) Different IgE reactivity profiles in birch pollen-sensitive patients from six European populations revealed by recombinant allergens: an imprint of local sensitization. Int Arch Allergy Immunol 128:325-335

Oberhuber $\mathrm{C}$ et al (2008) Characterization of Bet $\mathrm{v}$ 1-related allergens from kiwifruit relevant for patients with combined kiwifruit and birch pollen allergy. Mol Nutr Food Res 52(2):S230-240. https:// doi.org/10.1002/mnfr.200800146

Shen Y, Delaglio F, Cornilescu G, Bax A (2009) TALOS+: a hybrid method for predicting protein backbone torsion angles from NMR chemical shifts. J Biomol NMR 44:213-223. https://doi.org/10. 1007/s10858-009-9333-z

Vranken WF et al (2005) The CCPN data model for NMR spectroscopy: development of a software pipeline. Proteins 59:687-696. https://doi.org/10.1002/prot.20449

Publisher's Note Springer Nature remains neutral with regard to jurisdictional claims in published maps and institutional affiliations. 